

\title{
La inacabada reforma psiquiátrica española: cuestiones sobre internamientos psiquiátricos no voluntarios y la ausencia de control judicial en los ingresos geriátricos Involuntary psychiatric hospitalization under spanish law: applicability of judicial control of psychiatric hospitalization to geriatric admissions
}

\author{
Ma Fernanda Moretón Sanz* \\ * Profesora contratada doctora. Departamento de Derecho civil UNED'. fmoreton@der.uned.es
}

\begin{abstract}
Abstrac:
This paper examines Spanish legislation regarding involuntary commitment to mental health care facilities, comparing two cases: patients who refuse to be placed in facilities where they will receive psychiatric treatment and the placement of individuals in geriatric centres who are expressly opposed to admission. While legislation holds that a judicial order must be obtained in the first case, intervention by judicial authorities is not necessary in the second. When individuals are committed against their will and involuntary placement is accompanied by detainment measures or the application of psychiatric treatment, the basic rights of individuals are clearly threatened. For this reason, we believe that in the second case intervention by judicial authorities should also be compulsory and as such provided for under Spanish case law.
\end{abstract}

Keywords: Disabled, Dependency, Mental IIIness, Mentally Disabled, Psychiatric, Internment, Legislation.

\section{Resumen:}

En este trabajo se analizará el régimen asistencial y jurídico de los internamientos psiquiátricos no voluntarios y se comparará con el de los ingresos en geriátricos. En general, y hasta bien entrado el siglo XX, el modelo de atención imperante era el manicomial, circunscrito a la reclusión del "alienado" o "demente" en un Hospital psiquiátrico provincial o municipal, sin observancia del control judicial ideado en 1885. En época de la República se emprende el cambio de paradigma hacia un modelo asistencial del "enfer-

\footnotetext{
1 Este trabajo es uno de los resultados de los Grupos de Investigación Consolidado "Protección civil de la persona", siendo Investigador responsable el Prof. Dr. D. Carlos Lasarte Álvarez, Catedrático de Derecho civil de la UNED y de "Perspectivas de futuro de las políticas de familia" de la Universidad de Alcalá.
} 
mo psíquico", así el internamiento no voluntario sólo podrá producirse por indicación médica, como medio de tratamiento y, en ningún caso, como privación correccional de libertad. El Decreto de 1931, vigente hasta 1983, impuso el control judicial de los ingresos no voluntarios. En este sentido, uno de los principios del Plan general de salud de 1985, era reducir las hospitalizaciones gracias al modelo integrado de salud mental y atención psiquiátrica.

Palabras clave: Discapacidad, Dependencia, Enfermedad Mental, Discapacidad Psíquica, Internamiento Psiquiátrico, Normativa, Reforma Psiquiátrica; Modelos asistenciales.

\section{Article info:}

Received: 20 / 11 / 2010 / Received in revised form: 11 / 01 /2011 Accepted: 13 / 01 / 2011 / Published online: 14/01/2011

\section{Introducción}

Muchos han sido los avances en la atención, tratamiento y, en su caso, rehabilitación, de las personas con enfermedad mental o con discapacidad intelectual. Con todo, a nadie se le oculta que se trata de una conquista contemporánea y que tiene aún que recorrer un largo trecho para su consecución definitiva. Su pasado inmediato es escasamente edificante, tal y como acredita la lectura de la exposición de motivos de alguna de las normas reguladoras del internamiento psiquiátrico no voluntario. Así, se reconoce lo siguiente: "uno de los problemas más descuidado en España es, sin duda alguna, el referente al diagnóstico y asistencia de los alienados" (Ministerio de Gobernación. 1925. "Real Orden de 28 de julio." Gaceta de Madrid n ${ }^{\circ}$ 210: 661). De modo que sin cuidados médicos, a los "dementes" se les privaba de libertad de forma provisional o definitiva, mediante su reclusión en manicomios, en cárceles o presidios.

Por su parte, el Derecho ha evolucionado de forma paralela a esta indefinición del modelo de atención de la enfermedad mental, sucediéndose, por tanto, regulaciones deficientes $y$, muchas veces, inobservadas en la práctica dada la general ausencia de medios y la propia demonización y estigmatización de la "locura".

En particular, en este trabajo nos centraremos en el desarrollo del régimen asistencial y jurídico de los internamientos psiquiátricos no voluntarios y se comparará con el de los ingresos en centros residenciales y geriátricos. En ambos supuestos el denominador común de la hipótesis de la exposición es la ausencia de consentimiento de la persona afectada, bien porque se opone a la medida o, sencillamente, porque su situación volitiva le impide emitir consentimiento en sentido alguno. 


\section{El internamiento no voluntario por razón de trastorno psíquico: del control gubernativoal judicial}

\section{Del modelo manicomial a la primera reforma psiquiátrica: el Decreto de 3 de julio de 1931 del Gobierno provisional de la República}

En términos generales, y hasta finales del siglo XIX, el modelo imperante para los supuestos de lo que ahora se conoce como internamiento psiquiátrico urgente, era el manicomial, circunscrito a la reclusión del "alienado" o "demente" en un Hospital psiquiátrico provincial o municipal, ajeno al incipiente sistema de beneficencia ${ }^{2}$. Sin embargo, la intervención judicial de estos internamientos sumarios ya estaba prevista desde finales del XIX (Ministerio de Gobernación. 1885. “Real Decreto de 19 de mayo". Gaceta de Madrid n 141: 511), si bien la medida se caracterizó por su general inobservancia.

El texto de la Real Orden de 23 de julio de 1925 abordaba el problema del diagnóstico y asistencia de los alienados y advertía, asimismo, que la legislación del momento no sólo estaba anticuada sino en desacuerdo con las tendencias científicas de la época. Describía un panorama desolador en donde los afectados estaban privados de todos sus derechos: "en la tristeza de sus patios pasan los días en plena inactividad... Cárceles y presidios alojan locos presos y presos locos, que de ambas modalidades existen ejemplos...."

En este sentido, el Real Decreto de 1925 perseguía que la Comisión para la renovación y control de los ingresos psiquiátricos formulase las reformas necesarias para la asistencia y la enseñanza de la Psiquiatría, pretensión materializada mediante Decreto de 3 de julio de 1931, del Gobierno provisional de la República, donde se establecieron diferentes filtros y controles a los internamientos no voluntarios sometidos a indicación médica, orden gubernativa o judicial ${ }^{3}$.

De modo que en época de la República se emprende el cambio de paradigma hacia un modelo asistencial del "enfermo psíquico", por lo que el internamiento no voluntario sólo podrá admitirse por indicación médica o por orden gubernativa como medio de tratamiento $y$, en ningún caso, como privación correccional de la libertad.

2 La Ley de Beneficencia de 20 de junio de 1849, había previsto la dotación de varios Hospitales de Dementes si bien sólo fue creado el de Santa Isabel de Leganés, por lo que la atención de los alienados se hacía depender de particulares, Diputaciones provinciales y Ayuntamientos.

3 Esta normativa fue, a su vez, reformada por el Decreto el 27 de mayo de 1932, afectando en particular al artículo 12 sobre los internamientos de urgencia; a su vez la Orden de 30 de diciembre de 1932 aclara el sentido del ingreso por orden gubernativa (Ministerio de Gobernación. 1931. "Decreto de 3 de julio". Gaceta de Madrid n 188: 186-189; Ministerio de Gobernación. 1932. "Decreto de 31 de mayo". Gaceta de Madrid n 153: 186-1891.603-1.604). 
El Decreto de 1931 que impuso el control judicial preceptivo de los ingresos no voluntarios estuvo vigente en nuestro país hasta 1983, momento de la reforma del Código civil en materia de tutelas. Como ahora veremos, en la incipiente era constitucional, el Plan general de salud mental de 1985 quería potenciaba la atención ambulatoria, la hospitalización psiquiátrica en hospitales generales, y en definitiva, un nuevo modelo integrado de los servicios de atención mental.

\section{Ley 13/1983 y artículo 211 del Código civil: Requisitos del internamiento según la doctrina del Tribunal Constitucional y del Tribunal Europeo de Derechos Humanos}

Por tanto, el Decreto republicano de 1931 estuvo vigente más de cincuenta años y la atención de la enfermedad mental requería una reforma integral del sistema y una mejora sanitaria. Muchas voces se alzaban en pro de la imperiosa modificación y, por lo que se refiere a la doctrina civilista, antes incluso de la aprobación de la Constitución, se había hecho eco de la grave inadecuación de este instituto, dado el cuantioso número de enfermos mentales ingresados sin incapacitar judicialmente ${ }^{4}$.

Por fin, la necesaria actualización del Derecho de Familia a los principios de la era constitucional se emprende, por la Ley 13/1983, de 24 de octubre, de reforma del Código civil en materia de tutela ${ }^{5}$.

En particular, se incorpora al Código civil el artículo 211 sobre el Internamiento de un presunto incapaz que literalmente decía:

“El internamiento de un presunto incapaz requerirá la previa autorización judicial, salvo que, razones de urgencia hiciesen necesaria la inmediata adopción de tal medida, de la que se dará cuenta cuanto antes al Juez, y, en todo caso, dentro del plazo de veinticuatro horas.- El Juez, tras examinar a la persona y oír el dictamen de un facultativo por él designado, concederá o denegará la autorización y pondrá los hechos en conocimiento del Ministerio Fiscal, a los efectos prevenidos en el artículo 203.- Sin perjuicio de lo previsto en el artículo 269.4, el Juez, de oficio, recabará información sobre la necesidad de proseguir el internamiento, cuando lo crea pertinente $y$, en todo caso, cada seis meses, en forma igual a la prevista en el párrafo anterior, y acordará lo procedente sobre la continuación o no del internamiento".

Por tanto, la reforma judicializaría esta actuación que se ventilaría, a partir de su entrada en vigor, por los trámites de la jurisdicción voluntaria. Deroga, por el Decreto de 3 de julio de 1931 que desde su aprobación por el Gobierno provisional de la

\footnotetext{
${ }^{4}$ Obra señera fue la de Bercovitz. 1976. De la marginación de los locos y el Derecho, Madrid; también Lacruz Berdejo. 1978. Elementos de Derecho Civil.

5 Vid., Lasarte Álvarez. (2010); Moretón Sanz. (2005-2010).
} 
República, fue capaz de sobrevivir casi cincuenta años de los que cinco lo fueron bajo el imperio de la Constitución.

En cuanto al nuevo artículo 211 del Código civil, la Sentencia del Tribunal Constitucional 104/1990, de 4 de junio, tuvo ocasión de pronunciarse acerca de los requisitos de esta intervención; así dictada en amparo, advierte que "la exigencia de autorización judicial para el internamiento, que es una consecuencia del reconocimiento constitucional del derecho de libertad, no regía en el momento en que ese internamiento se produjo (...), el control judicial previsto para el internamiento ha de entenderse que comprende también las decisiones sobre la modificación o la terminación del internamiento, a través de las vías previstas en la LEC, con la posible intervención del procedimiento de habeas corpus sólo en la medida en que esas vías judiciales ordinarias se hayan mostrado inidóneas para proteger la libertad".

En este sentido, uno de los principios del Plan general de salud de 1985, era reducir las hospitalizaciones y dirigirse hacia un modelo integrado de salud mental y atención psiquiátrica. Entre sus Recomendaciones y propuestas se encontraba la relativa a la materia que se estudia: "6. Se han de contemplar en la normativa sanitaria los criterios de protección de los derechos civiles del usuario de servicios psiquiátricos recogidos en la reforma del Código civil en materia de tutela (Ley 13/1983, de 24 de octubre), especialmente en cuanto a los reconocimientos, tratamientos y hospitalización llevados a cabo sin consentimiento expreso del paciente. 7. De forma transitoria, el Ministerio de Sanidad y Consumo y el Ministerio de Justicia, acordarán los criterios de aplicación de dicha Ley en relación a la hospitalización psiquiátrica. Igualmente y a nivel nacional, impulsarán la creación de una comisión que estudie la situación jurídica de los pacientes ingresados en las instituciones psiquiátricas, para promover la protección de sus derechos civiles y el cumplimiento de dicha Ley" (Comisión Ministerial para la Reforma Psiquiátrica. 1985. "Documento General y Recomendaciones para la reforma psiquiátrica y la atención a la salud mental". Rev. Asoc. Esp. Neuropsiquiatría n¹3: 218).

\section{La reforma del artículo 211 del Código civil por Ley Orgánica 1/1996 y la cuestión de inconstitucionalidad ventilada por la STC 129/1999}

Por su parte, la LO 1/1996, de 15 enero, de Protección Jurídica del Menor, modifica tanto el Código civil como la Ley de Enjuiciamiento Civil; así, su Disposición final duodécima retoca el primer párrafo del artículo 211 del Código civil que pasaría a tener la siguiente redacción: “El internamiento por razón de trastorno psíquico, de una persona que no esté en condiciones de decidirlo por sí, aunque esté sometida a la patria potestad, requerirá autorización judicial. Ésta será previa al internamiento, salvo que razones de urgencia hiciesen necesaria la inmediata adopción de la medida, de la que se dará cuenta cuanto antes al Juez y, en todo caso, dentro del plazo de veinticuatro horas. El internamiento de menores, se realizará en todo caso en un 
establecimiento de salud mental adecuado a su edad, previo informe de los servicios de asistencia al menor".

Su Exposición de Motivos daba el sentido de la reforma del 211 del Código civil en los siguientes términos: "Otra cuestión que se aborda en la Ley es el internamiento del menor en centro psiquiátrico y que con el objetivo de que se realice con las máximas garantías por tratarse de un menor de edad, se somete a la autorización judicial previa y a las reglas del artículo del Código civil, con informe preceptivo del Ministerio Fiscal, equiparando, a estos efectos, el menor al presunto incapaz y no considerando válido el consentimiento de sus padres para que el internamiento se considere voluntario, excepción hecha del internamiento de urgencia".

Consecuencia de una cuestión de inconstitucionalidad sobre el artículo 211 del Código civil, el Tribunal Constitucional intervino nuevamente. En el supuesto de autos, una Trabajadora social que atendía la situación de riesgo que presentaba una menor, a la vista de la situación de la madre de la niña, interesó del Juzgado el internamiento de la progenitora en un centro psiquiátrico.

La STC 129/1999, de 1 de julio, recapitula tanto la doctrina previa como la sentada por el Tribunal Europeo de Derechos Humanos, advirtiendo, sobre los presupuestos del internamiento en un centro psiquiátrico que "sólo será conforme con la Constitución y con el Convenio si se dan las siguientes condiciones, sentadas en la STEDH de 24 de octubre de 1979 (caso Winterwerp) y reiteradas en las de 5 de noviembre de 1981 (caso X contra Reino Unido) y de 23 de febrero de 1984 (caso Luberti): 'a) Haberse probado de manera convincente la enajenación mental del interesado, es decir, haberse demostrado ante la autoridad competente, por medio de un dictamen pericial médico objetivo, la existencia de una perturbación mental real; b) que ésta revista un carácter o amplitud que legitime el internamiento, y c) dado que los motivos que originariamente justificaron esta decisión pueden dejar de existir, es preciso averiguar si tal perturbación persiste y, en consecuencia, debe continuar el internamiento en interés de la seguridad de los demás ciudadanos, es decir, no puede prolongarse válidamente el internamiento cuando no subsista el trastorno mental que dio origen al mismo'".

Declara el TC que "todas estas condiciones quedan satisfechas plenamente en el procedimiento regulado en el art. 211 Código civil. Se prevé, de un lado, como no podía ser menos, que el internamiento sólo puede verificarse previa autorización judicial, salvo que razones de urgencia hicieran necesario el internamiento inmediato, supuesto en el que, en todo caso, será preciso ponerlo en conocimiento de la autoridad judicial dentro del plazo de veinticuatro horas (art. 211.1\%). La autorización sólo podrá ser concedida por el Juez 'tras examinar a la persona y oír el dictamen de un facultativo por él designado' (art. $211.2^{\circ}$ ) y nunca se adoptará con carácter indefinido, pues el órgano judicial, 'de oficio, recabará información sobre la necesidad de proseguir el internamiento, cuando lo crea pertinente y, en todo caso, cada seis meses', acordando entonces, también tras examinar al internado y oír el dictamen de un facultativo, 'lo procedente sobre la continuación o no del internamiento' (art. 211.3).". 
De modo que desestima la cuestión ya que "en definitiva, el panorama normativo que acaba de describirse, y que entendemos de obligado cumplimiento, pone de manifiesto la inexistencia de las deficiencias denunciadas por el órgano judicial proponente de la cuestión. La privación de libertad que supone todo internamiento ex art. 211 Código civil se ajusta a las exigencias derivadas del art. 17.1 de la CE en la medida en que sólo puede ser acordada en virtud de autorización judicial, adoptada en virtud de una norma previa que regula su actuación. En efecto, el procedimiento de adopción de la decisión judicial de internamiento encuentra en las disposiciones contenidas en el propio art. 211 Código civil y en los arts. 1.811 a 1.824 LEC un desarrollo conforme con los derechos fundamentales reconocidos en los dos apartados del art. 24 de la CE, toda vez que se asegura la audiencia de la persona afectada, se hace posible su oposición al internamiento y concluye con una autorización de naturaleza transitoria necesariamente revisable en plazos de tiempo razonables y sólo adoptada tras haberse acreditado, mediante la práctica de las pruebas oportunas y tras oír el dictamen de, al menos, un facultativo, que la medida de internamiento aparece como la más conveniente en beneficio del propio afectado y de la comunidad". Consta voto particular que por razones de espacio no procede su transcripción si bien conviene tenerlo en cuenta ya que ratifica las insuficiencias de este procedimiento ya evidenciadas por la Circular de la Fiscalía 2/1984, sobre el presupuesto habilitante, los sujetos legitimados y la propia oposición al proceso.

De modo que transcribe y reitera la doctrina de la STC 112/1988, de 8 de junio y anticipa al tiempo las resoluciones delTEDH que se pronunciarían después en idéntica línea de las citadas expresamente.

Baste su referencia así la STEDH de 28 de marzo de 2006, en el asunto Gaultier contra Francia; 12 de junio de 2003, Herz contra Alemania, que declara la violación del artículo 5.4 del Convenio ante la ausencia de control de legalidad del segundo internamiento provisional del demandante; de 18 de junio de 2002, asunto Delbec contra Francia estimatoria ante la falta del cumplimiento del breve plazo para su solicitud de libertad; la importante para el objeto de estudio de 26 de febrero de 2002, asunto H.M. contra Suiza, desestimatoria, sobre el internamiento en residencia de ancianos por demencia senil. En esta resolución conviene destacar la opinión disidente del Juez Loucaides habida cuenta de que a su juicio sí que existió privación ilícita de libertad de la anciana toda vez que carecía de la posibilidad de abandonar el centro; la de 29 de marzo de 2001 dictada en el asunto D.N. contra Suiza, estimatoria ante la falta de imparcialidad de un miembro de la comisión de recursos administrativos sobre su petición de liberación de una clínica psiquiátrica (con votos disidentes); la de 2 de septiembre de 1998, en el asunto Erkalo contra Países Bajos, estimatoria de la demanda ante la detención ilegal transcurrida entre la solicitud de liberación del Centro psiquiátrico donde cumplía condena y su concesión por el Tribunal competente; 30 de julio de 1997, asunto Aerts contra Bélgica, estimatoria parcial ante sufrimiento moral por la detención provisional en el anexo psiquiátrico del centro penitenciario; 12 de mayo de 1992 asunto Megyeri contra Alemania; 21 de febrero de 1990, asunto Van der Leer contra los Países Bajos, estimatoria ante la falta de cum- 
plimiento de los requisitos del internamiento en centro psiquiátrico; la de 28 de noviembre de 1988 asunto Nielsen contra Dinamarca, sobre la hospitalización de un menor a petición de la titular de la patria potestad, desestimatoria pese a los votos disidentes (incluido el de CARRILLO SALCEDO) ante la falta de libertad que presentó el internamiento del menor. Por su parte y recogidas en la STC, conviene tener presente la Sentencia 28 de mayo de 1985 (asunto Ashingdane contra Reino Unido) desestimatoria en tanto no se discute la legalidad del internamiento sino el centro; la de 23 de febrero de 1984 asunto Luberti contra Italia, que estima parcialmente la demanda ante la existencia de dilaciones en el procedimiento de control judicial de la solicitud del levantamiento de la medida de internamiento psiquiátrico; 5 de noviembre de 1981, asunto X contra Reino Unido que estima parcialmente la demanda por la orden de reinternamiento contraria al derecho a la libertad incumpliendo las garantías judiciales y la de 24 de octubre de 1979 (asunto Winterwerp contra Países Bajos) que estima la demanda ante la violación del art 5.4 del Convenio al carecer el internamiento de urgencia de recurso ante órgano jurisdiccional y ausencia de garantías procedimentales en proceso sobre bienes y obligaciones civiles.

\section{La LEC de 2000 y el nuevo artículo 763 sobre el internamiento no voluntario por razón de trastorno psíquico ventilado por los cauces de un contencioso sui generis: La Circular 1/2001 de la Fiscalía}

Finalmente el discutido artículo 211 del Código civil fue derogado por la nueva LEC $^{6}$ y sustituido por las prescripciones del 763 incluido en el Libro cuarto de los procesos especiales, título primero De los procesos sobre capacidad, filiación, matrimonio y menores, procesos que se ventilarán por los trámites del juicio verbal con ciertas especialidades referidas en el artículo 753.

Dice este artículo 763: "1. El internamiento, por razón de trastorno psíquico, de una persona que no esté en condiciones de decidirlo por sí, aunque esté sometida a la patria potestad o a tutela, requerirá autorización judicial, que será recabada del tribunal del lugar donde resida la persona afectada por el internamiento.- La autorización será previa a dicho internamiento, salvo que razones de urgencia hicieren necesaria la inmediata adopción de la medida. En este caso, el responsable del centro en que se hubiere producido el internamiento deberá dar cuenta de éste al tribunal competente lo antes posible y, en todo caso, dentro del plazo de veinticuatro horas, a los efectos de que se proceda a la preceptiva ratificación de dicha medida, que deberá efectuarse en el plazo máximo de setenta y dos horas desde que el internamiento llegue a conocimiento del tribunal.- En los casos de internamientos urgentes, la competencia para la ratificación de la medida corresponderá al tribunal del lugar en que radique el centro donde se haya producido el internamiento. Dicho tribunal deberá actuar, en su caso, conforme a lo dispuesto en el apartado 3 del artícu-

${ }^{6}$ Disposición derogatoria única punto segundo. 
lo 757 de la presente Ley. 2. El internamiento de menores se realizará siempre en un establecimiento de salud mental adecuado a su edad, previo informe de los servicios de asistencia al menor. 3. Antes de conceder la autorización o de ratificar el internamiento que ya se ha efectuado, el tribunal oirá a la persona afectada por la decisión, al Ministerio Fiscal y a cualquier otra persona cuya comparecencia estime conveniente o le sea solicitada por el afectado por la medida. Además, y sin perjuicio de que pueda practicar cualquier otra prueba que estime relevante para el caso, el tribunal deberá examinar por sí mismo a la persona de cuyo internamiento se trate y oír el dictamen de un facultativo por él designado. En todas las actuaciones, la persona afectada por la medida de internamiento podrá disponer de representación y defensa en los términos señalados en el artículo 758 de la presente Ley.- En todo caso, la decisión que el tribunal adopte en relación con el internamiento será susceptible de recurso de apelación. 4. En la misma resolución que acuerde el internamiento se expresará la obligación de los facultativos que atiendan a la persona internada de informar periódicamente al tribunal sobre la necesidad de mantener la medida, sin perjuicio de los demás informes que el tribunal pueda requerir cuando lo crea pertinente.- Los informes periódicos serán emitidos cada seis meses, a no ser que el tribunal, atendida la naturaleza del trastorno que motivó el internamiento, señale un plazo inferior.- Recibidos los referidos informes, el tribunal, previa la práctica, en su caso, de las actuaciones que estime imprescindibles, acordará lo procedente sobre la continuación o no del internamiento.- Sin perjuicio de lo dispuesto en los párrafos anteriores, cuando los facultativos que atiendan a la persona internada consideren que no es necesario mantener el internamiento, darán el alta al enfermo, y lo comunicarán inmediatamente al tribunal competente"7.

Con todo y pese a la reconducción de este internamiento a los trámites del contencioso, tanto la doctrina como la jurisprudencia cuestionan la auténtica naturaleza del proceso en tanto en cuanto en aquellos asuntos en que el interesado esté privado de capacidad volitiva, carece de su bilateralidad característica ${ }^{8}$.

7 Vid., Zurita Martín. 2008. “El internamiento de personas mayores en centros geriátricos o residenciales", Responsabilidad derivada del internamiento de personas mayores dependientes en centros residenciales. Pp. 19-66; Calaza López. 2007. Los procesos sobre la capacidad de las personas. Pp. 257-314; Sillero Crovetto. 2007. “El internamiento no voluntario por razón de trastorno psíquico". La protección de las personas mayores. Pp. 162-178; Serrano García. 2004. “Discapacidad e Incapacidad en la Ley 41/2003, de 18 de noviembre". Estudios de Derecho Civil: homenaje a Serrano García. Pp. 93-130; Duro Ventura. 1995. "El internamiento de los presuntos incapaces. Introducción. Cuestiones procesales". Salud Mental y justicia. Cuadernos de Derecho Judicial. Pp. 9-38; Lacaba Sánchez. 1995, “El internamiento de los presuntos incapaces. Aspectos materiales". Salud Mental y justicia. Cuadernos de Derecho Judicial. Pp. 39 -90.

8 Reclama la reconducción a la jurisdicción voluntaria Calaza López (pp. 263 ss.); la cuestiona también Zurita Martín (pp. 56 ss.) y así se han tramitado distintos supuestos como, entre otros, el ventilado por el AAP de Cádiz de 27 de mayo de 2008 sobre solicitud de autorización judicial de internamiento en Residencia; ATSupJ Valencia de 17 de octubre de 2006 y el A de 31 de enero de 2006; AAP de Huelva de 24 de julio de 2006, de internamiento en Centro residencial; o la SAP de Segovia de 17 de noviembre de 2003. 
En aquel sentido, la Circular 1/2001, de 5 de abril, sobre la incidencia de la nueva LEC en la intervención del Fiscal en los procesos penales advierte, por lo que a los internamientos no voluntarios del 763 afecta, que el proceso verbal con contestación escrita de la demanda es incompatible con la celeridad que debería rodear a este ingreso ${ }^{9}$.

\section{La futura reforma de los procedimientos de modificación de la capacidad de obrar y los nuevos pronunciamientos del TC SS 131 y 132/2010}

No está cerrado el sistema procesal, antes bien ha de tenerse en cuenta la Ley 1/2009, de 25 de marzo, de Reforma de la Ley de 8 de junio de 1957, sobre el Registro Civil, en materia de incapacitaciones, cargos tutelares y administradores de patrimonios protegidos y de la Ley $41 / 2003$, de 18 de noviembre, sobre protección patrimonial de las personas con discapacidad y de modificación del Código civil, de la LEC y de la normativa tributaria con esta finalidad ya que contempla la reforma de la legislación reguladora de los procedimientos de modificación de la capacidad de obrar, para adaptarlo a la Convención Internacional sobre los Derechos de las personas con discapacidad de las NNUU de 13 de diciembre de $2006^{10}$. De modo que no descartamos la reforma y tipificación de alguno de los extremos más conflictivos de este internamiento como los ingresos en centros residenciales y los tratamientos ambulatorios no voluntarios ${ }^{11}$.

Recientemente elTribunal Constitucional ha instado al legislador para que dote de la condición de Ley orgánica a la norma que prevé el internamiento, toda vez que se trata de una medida privativa de libertad. Se trata de los pronunciamientos de las SSTC 131 y 132/2010.

9 Vid., Circular 2/1984, de 8 de junio, sobre internamiento de presuntos incapaces; Instrucción 6/1987, de 23 de noviembre, sobre control por el Ministerio Fiscal de los internamientos psiquiátricos; Instrucción 3/1990, de 7 de mayo, sobre régimen jurídico que debe de regir para el ingreso de personas en residencias de la tercera edad, vigente según la Conclusión primera de la Instrucción 4/2008, de 30 de julio, sobre el control y vigilancia por el Ministerio Fiscal de las tutelas de personas discapaces.

10 Sobre la UE y al Consejo de Europa y la Convención de la ONU sobre los Derechos de las personas con discapacidad, de 13 de diciembre de 2006, vid., Moretón Sanz. (2006). "Apuntes sobre la Constitución Europea y el derecho a la no discriminación de las personas con discapacidad", RFDUNED. Pp. $247-272$ y (2010) "Nuevas perspectivas jurídicas en materia de no discriminación por razón de edad, discapacidad o dependencia)", Discriminación por razón de edad y de sexo. Pp. 37.

11 DF $1^{\mathrm{a}}$. En este sentido, recuérdese el retirado Proyecto de Ley de Jurisdicción voluntaria que contemplaba la autorización judicial de los tratamientos no voluntarios de las personas con trastornos psíquicos, eliminado trámite de enmiendas. Como novedad interesante destaca el impulso que la Audiencia de Alicante ha dado al Protocolo para dar solución a situaciones de riesgo en casos de enfermedades mentales, evidenciándose también la conveniencia de crear un Juzgado específico en materia de Salud mental para los tratamientos ambulatorios. 


\section{El derecho a decidir libremente el ingreso en centro residencial según la Ley 39/2006}

\section{El derecho a decidir el ingreso residencial según el artículo cuarto de la Ley 39/2006 y el proceso contradictorio}

La persona que pretenda el ejercicio de cualquiera de los derechos previstos en la Ley 39/2006, de 14 de diciembre, de Promoción de la Autonomía Personal y Atención a las personas en situación de dependencia, tendrá que acreditar previamente el Grado de dependencia reconocido. Por tanto, no resulta suficiente alegar la existencia de una avanzada edad, la evidencia material de una discapacidad, o una sentencia de incapacitación, toda vez que se trata de un derecho subjetivo que de conformidad a la mencionada Ley 39/2006, exige el reconocimiento previo de la situación de dependencia.

Sin embargo, abogamos por la aplicación analógica - pese a la contradictoria jurisprudencia menor dictada en la materia ${ }^{12}-$ del proceso sobre internamientos no voluntarios al ingreso no voluntario o avoluntario en centro residencial. En puridad, al tratarse de un derecho fundado en la propia libertad individual del sujeto, sea o no titular del nuevo derecho subjetivo de ciudadanía no resulta desproporcionado legalizar el ingreso en Residencia cuando no concurra la anuencia del interesado, esté o no en situación de dependencia reconocida.

En este sentido, ha de tenerse en cuenta su artículo cuarto del que cabe destacar su punto 2 letra g) por cuanto declara sobre los derechos y obligaciones de las personas en situación de dependencia, que disfrutarán de todos los establecidos en la legislación vigente, específicamente el de "decidir libremente sobre el ingreso en centro residencial". Inmediatamente después, la letra h) advierte sobre el ejercicio pleno de sus derechos jurisdiccionales que, en el caso de internamientos involuntarios, habrá de garantizarse un proceso contradictorio. A renglón seguido el precepto impone a los poderes públicos ciertas obligaciones ya que "adoptarán las medidas necesarias para promover y garantizar el respeto de los derechos enumerados".

Gracias al elenco de derechos reconocidos para las personas en situación de dependencia se refuerzan los intereses ya amparados por el ordenamiento civil y procesal y dispuesto en favor de personas en situaciones desfavorecidas, sea por razón de edad, género, enfermedad o pérdida de capacidad natural, etc. Dicha relación legal evidencia y reclama la necesaria sistematización y la deseable normativa futura que unifique la disparidad del ordenamiento y garantice los derechos de las personas en situaciones especiales.

12 En contra de la necesidad de legalización del ingreso y de la aplicación analógica del procedimiento de este 211 se pronuncia la SAP de Barcelona de 24 de julio de 1996. 


\section{La voluntariedad del ingreso en centros residenciales como derecho de la personas en situación de dependencia: aplicabilidad analógica y extensiva de la homologación y control judicial a la totalidad de ingresos involuntarios y avoluntarios}

Contempla también la Ley 39/2006 la obligatoriedad del Reglamento de Régimen interior cuya existencia y homologación administrativa, reforzará el protagonismo del usuario en el funcionamiento del Centro y redundará en la garantía de los derechos de las personas internadas ${ }^{13}$.

Recuérdese asimismo que parte de la contradictoria doctrina jurisprudencial de las Audiencias encuentra, a su vez, fundamento en la normativa autonómica previa toda ella a la Ley 39/2006. En este sentido, se evidencia el ejercicio intenso de los capítulos competenciales en materia de Asistencia y Servicios Sociales y protección de la tercera edad por parte de las CCAA. Sin embargo, dicha profusión normativa ha provocado, a su vez, un panorama legislativo en materia de recursos residenciales disperso, en ocasiones antitético y, por lo que se refiere a la voluntariedad del ingreso, carente de criterios unitarios en el territorio español ${ }^{14}$.

Como decimos, en los últimos años Juzgados y Tribunales han tenido multitud de ocasiones para pronunciarse sobre los ingresos involuntarios y sus consecuencias $^{15}$.

Por tanto y de conformidad al artículo $4.2 \mathrm{~g}$ ) de la Ley 39/2006, el ordenamiento jurídico estatal español contempla, por primera vez, una previsión explícita sobre el derecho del interesado a rechazar el ingreso en un centro residencial. Hasta este momento, no contábamos siquiera con una referencia que recogiese la posibilidad de negarse a un ingreso en un centro, cuya actividad principal como sabemos no consiste en exclusiva en la prestación de servicios médicos psiquiátricos especializados.

La pretensión de extender este control judicial de los internamientos a los ingresos residenciales ha recibido dispar fortuna en las Audiencias. En ocasiones la desestimación de emitir autorización judicial se justifica en que en estos centros no necesariamente se proporcionan servicios psiquiátricos especializados, todo ello sin

13 “Artículo 35. Calidad en la prestación de los servicios. 2. Los centros residenciales para personas en situación de dependencia habrán de disponer de un reglamento de régimen interior, que regule su organización y funcionamiento, que incluya un sistema de gestión de calidad y que establezca la participación de los usuarios, en la forma que determine la Administración competente".

14 Vid., Casas Planes (2007). "Reflexión acerca del daño moral al enfermo psíquico derivado de actuaciones judiciales y del funcionamiento anormal de la Administración Pública (propuesta de lege ferenda)", La Ley, 6.697. Por su parte, Defensor del Pueblo. 1991. Informes, estudios y documentos y recomendaciones sobre la situación jurídica y asistencial del enfermo mental en España.

15 En este sentido, vid. la SAP de Albacete de 19 de abril de 2006 ratifica la condena en instancia de los hijos de la demandante por los daños sufridos en virtud del ingreso en centro residencial ordenado por estos descendientes y en contra de la voluntad de la interesada. 
apreciar ni atender a la caracterización legal de las Residencias como centros sanitarios dedicados de forma no exclusiva a esta actividad ${ }^{16}$.

En síntesis, no deduciéndose de dicho ingreso la aplicación de medidas sanitarias ni privándose de libertad deambulatoria al interesado, jueces y magistrados han declinado intervenir.

Empleando el anterior argumento a contrario, la concurrencia de medidas que incidan en la libertad deambulatoria del interesado debería ser causa suficiente para fundar la conveniencia de la convalidación judicial del ingreso. Es el supuesto ventilado por el AAP de Segovia, de 27 de marzo de 2000, que declara que "la acogida de personas de tercera edad con etiología de las diversas demencias enumeradas o cualquier enfermedad de tipo psíquico, que determine su posible incapacidad, en hospital o residencia, en cuanto no se le permita salir de la misma en cualesquiera circunstancias que sea, equivale a detención a los efectos del artículo 5.1 e) del Convenio Europeo de Derechos Humanos ${ }^{17}$ y por ende precisa autorización de dicho internamiento (detención) por la autoridad judicial"18.

\section{Cuestiones sobre las residencias y la convenencia de la homologación judicial de los ingresos involuntarios y avoluntarios}

\section{La condición jurídica del residente como usuario y la naturaleza de las residencias como centros integrados en servicios sanitarios no exclusivos}

A mayor abundamiento, téngase en cuenta que el sistema y las bases para la autorización de centros, servicios y establecimientos sanitarios, está previsto con carácter general por el Real Decreto 1.277/2003, de 10 de octubre, destacándose que entre sus previsiones se encuentran las de aquellos centros públicos o privados, subsumibles en el epígrafe de residencias, caracterizadas éstas por tratarse de un servicio sanitario integrado en una organización no exclusivamente de esta naturaleza ${ }^{19}$.

16 En la materia, vid., Martín Pérez, (2004). “El internamiento o ingreso de personas mayores en centros geriátricos. Acerca de la procedencia de autorización judicial cuando el ingreso es involuntario", Protección jurídica de los mayores. Pp. 167-192; vid., tanto las resoluciones judiciales de las Audiencias como la bibliografía citada en Moretón Sanz, (2010). Residencias y alojamientos alternativos para personas mayores en situación de dependencia.

17 Dice este artículo 5.1: “Toda persona tiene derecho a la libertad y a la seguridad. Nadie podrá ser privado de su libertad, salvo en los casos siguientes y con arreglo al procedimiento determinado por ley: e) si se trata de la detención legal de una persona susceptible de propagar una enfermedad contagiosa, de un enajenado mental, un alcohólico, un toxicómano o un vagabundo".

18 Afirma la SAP Segovia de 17 de febrero de 2004 que será de aplicabilidad el 763 "cuando el internamiento sea por razón de trastorno psíquico con independencia de que el Centro donde se encuentre el internado pueda ser una residencia geriátrica o una residencia dedicada al cuidado de trastornos psíquicos".

19 En particular, el Anexo II "Definiciones de centros, unidades asistenciales y establecimientos sanitarios", en el epígrafe de Centros sanitarios, incluye en el apartado C.3. los "servicios sanitarios integra- 
A estos extremos y a esta consideración de las Residencias como Centros Sanitarios se añade, por parte delTribunal Supremo y por ende de la jurisprudencia menor, la aplicabilidad de las prescripciones del ahora Real Decreto Legislativo 1/2007, de 16 de noviembre, por el que se aprueba el Texto refundido de la Ley General para la Defensa de los Consumidores y Usuarios y otras leyes complementarias ${ }^{20}$. En definitiva, el interno tiene la consideración jurídica de usuario, sea en régimen de prestación pública o privada y goza, en su virtud, de los derechos y de la tutela de aquella norma ${ }^{21}$.

\section{La residencia como domicilio y la libertad deambulatoria del interno: intimidad versus medidas terapéuticas o inmovilizadoras para la prevención de fugas}

La naturaleza del centro residencial como sede permanente del usuario, obliga a detenerse siquiera sea brevemente en los aspectos y consecuencias de su ingreso - permanente o temporal-, toda vez que su esfera de protección resulta ampliada en virtud de la especial tuición que el ordenamiento reserva a la sede jurídica de la persona. En este sentido, conviene destacar que el domicilio del mayor ingresado, voluntariamente o no, en una residencia o interno un sistema alternativo de alojamiento es, precisamente, el centro y que con ello, gozará también del singular amparo del espacio donde se desenvuelve la esfera más íntima del ser humano ${ }^{22}$.

Especial relieve adquieren los controles de entrada y salida de usuarios en los centros residenciales así como la implantación de las "pulseras" localizadoras en sus internos. En este punto conviene destacar la tensión existente entre los derechos en conflicto, ante el especial interés del centro en evitar y prevenir comportamientos fuguistas en personas que al presentar deterioro cognitivo sufren de una acusada desorientación y pueden resultar incapaces de regresar al lugar de origen ${ }^{23}$.

dos en una organización no sanitaria: servicios que realizan actividades sanitarias pero que están integrados en organizaciones cuya principal actividad no es sanitaria (prisión, empresa, balneario, residencia de tercera edad)".

20 Vid., artículo 8 sobre los derechos básicos, y el 59, 60 y 61 sobre contratación. Por su parte, Plaza Penadés, sistematiza con rigor los cambios en materia de responsabilidad médica y sanitaria (vid., 2002. “La Ley 41/2002, básica sobre autonomía del paciente, información y documentación clínica", Actualidad jurídica Aranzadi). En materia de consumo, vid., Lasarte Álvarez, Manual sobre protección de consumidores y usuarios, Madrid, 2007, $3^{\text {a }}$ ed.

${ }^{21}$ En este sentido, el RD 1.277/2003 mencionado, concreta las previsiones de la 16/2003, de 28 de mayo, de Cohesión y calidad del Sistema nacional de salud, muy especialmente en sus garantías de seguridad (arts 26 y 27.3). En cuanto a la Ley 14/1986, de 25 de abril, General de Sanidad, sobre autorización administrativa de centros y establecimientos sanitarios, arts 29 y 40.

22 Y ello pese a las dudas puestas de manifiesto por Juzgados y Tribunales sobre la viabilidad de la Residencia como domicilio.

${ }^{23}$ AAP de Sevilla de 21 de octubre de 2003. Por mucho que se quiera y pese a que una medida de esta naturaleza se aplique a sujetos que presenten deterioro cognitivo y tenga como intención la prevención de daños, es dudoso que pueda ampararse en dicha finalidad cautelar. Por su parte y dentro de los servicios prestados por las entidades locales, últ y en el marco de laTeleasistencia, también se proporcionan GPS o localizadores para adultos con Alzheimer. 


\section{Recapitulación sobre la contradictoria jurisprudencia menor en materia de homologación judicial de los ingresos residenciales de personas con deterioro cognitivo}

Por tanto el artículo cuarto de la Ley 39/2006 colma ciertas lagunas - siquiera parcialmente - como la planteada en los supuestos de ingreso en centro residencial no voluntario o calificable de "avoluntario", ante la imposibilidad material de elaborarla caso de que el interesado presente ciertos síndromes.

Por primera vez el ordenamiento jurídico estatal contempla de forma expresa el requisito de la voluntariedad para el ingreso en centros residenciales. Si estaba prevista la necesidad de autorización judicial para el internamiento psiquiátrico no voluntario, incluso para menores o mayores incapacitados, nada se había declarado sobre la anuencia del interesado o de examen contradictorio si el sujeto se opusiera al ingreso. Con todo, existían algunas disposiciones en ciertas CCAA que hacían preceptivo el consentimiento del afectado o, en su defecto, la autorización para el ingreso. En este sentido, la SAP de Huelva, de 20 de marzo de 2007 declara que "el presupuesto de partida para que pueda aplicarse el artículo 763 de la LEC es que la persona a internar no pueda decidir por sí misma por razón del trastorno psíquico, esto es, que no pueda prestar válidamente su consentimiento ni al momento de ingresar ni durante el tiempo que dure el internamiento. El internamiento será involuntario desde el momento en que el anciano no pueda prestar válidamente su consentimiento al mismo. Faltando su consentimiento, se hace necesaria la intervención judicial para controlar el internamiento, en aras de la protección de las personas con discapacidad psíquica, sean enfermos mentales o ancianos con demencia senil o disminuidos psíquicos" 24 .

El ejercicio del conjunto de derechos y facultades depende, a su vez, de la propia capacidad de obrar del sujeto titular por lo que, en su caso, deberán ser reclamados o instada su reposición por el representante legal sea éste tutor, público o privado, o curador.

Este derecho a "decidir libremente sobre el ingreso en centro residencial", resulta uno de los aciertos más destacables de la Ley. En buena lógica parece que, en tanto no se apruebe otro procedimiento, el aplicable será el previsto en la LEC para el internamiento no voluntario por razón de trastorno psíquico. De modo que en aque-

24 En cuanto al AAP Huelva de 6 de marzo de 2007, favorable a la aplicabilidad del artículo 763 a "otros casos como son los de personas que se encuentran en unidades hospitalarias no psiquiátricas deprivados de conciencia y voluntad (en coma por ejemplo) o ancianos ingresados en centros asistenciales que bien por enfermedad específica o por los propios cursos de deterioro senil tampoco están en condiciones de comprender su situación ni de decidir en consecuencia". También AAP Huelva de 24 de julio de 2006; AAP Huelva de 28, 23, 14, 10, 9 de septiembre de 2004, revocatorios del archivo del proceso de homologación del internamiento en centro asistencial para personas mayores procedentes todos ellos del Juzgado de La Palma del Condado. Por su parte, el AAP Toledo, de 16 de enero de 2003, también estima la necesidad de autorización judicial para el internamiento asistencial en residencia de tercera edad, si el ingreso no es voluntario. 
Ilos supuestos en que el sujeto en situación de dependencia vea comprometida su libre decisión sobre el ingreso en un centro residencial o geriátrico se ventilará en vía judicial el interés al que se deba dar preferencia ${ }^{25}$.

A mayor abundamiento, tal y como ya ha sucedido con alguna de las previsiones de la Ley 41/2003 sobre la exclusión de venta en pública subasta aplicada a los casos de enajenación de bienes del incapaz ${ }^{26}$, cabe augurar la aplicación analógica de este derecho sobre el ingreso en centro residencial y, en su caso, del procedimiento judicial contradictorio que garantice el pleno respeto a su voluntad, tanto a las personas en situación de dependencia como a las que no lo estén, muy especialmente, en el caso de mayores. Apréciese que esté incapacitado o no, ostente o carezca de una certificación de discapacidad, se le haya reconocido o no la situación de dependencia, existe una evidente identidad de razón entre el respeto a la oposición al ingreso y el reconocimiento de este derecho ${ }^{27}$.

\section{Conclusiones}

El modelo y la propia ausencia de patrones para la atención de las personas con enfermedad mental o discapacidad intelectual, evidencia una evolución normativa que debería dirigirse con más entusiasmo hacia los derechos de los pacientes y ampliarse, en el denominado cuarto pilar del Estado social, al de los usuarios de los geriátricos.

Recientemente elTribunal Constitucional español ha instado al legislador para que dote de la condición de Ley orgánica a la norma que prevé el internamiento psiquiátrico no voluntario, toda vez que se trata de una medida privativa de libertad, oportunidad que podría ser aprovechada por el poder legislativo para resolver las incertidumbres sobre los centros residenciales.

${ }^{25}$ Como decimos, no existe una única línea jurisprudencial que se pronuncie de forma unívoca sobre la necesidad de autorización judicial en casos de internamiento en centros asistenciales y no psiquiátrico, contemporizada esta afirmación también por la distinta normativa de cada CCAA en materia de asistencia social y recursos residenciales.

${ }^{26}$ Vid., Moretón Sanz. 2006. “La figura del administrador del patrimonio especialmente protegido: reflexiones sobre su régimen jurídico", Libro Homenaje al Prof. Amorós Guardiola. P. 1.196.

27 Chimeno Cano estima debería ser distinto el tratamiento que ha de recibir el ingreso en un geriátrico cuando sea como centro de atención psiquiátrica que es el único que podría realizarse contra la voluntad del mayor pero con autorización judicial; los ingresos en cualesquiera centros residenciales en buena lógica deberán depender de la voluntad del interesado (vid. 2000. “El ingreso forzoso de ancianos en centros especializados", Aranzadi). Por su parte, Zurita Martín, se inclina favorablemente hacia las tesis que mantienen la necesidad de autorización judicial incluso para un centro asistencial, habida cuenta de que en ellos se priva o limita la libertad deambulatorio del mayor (2004). Gete-Alonso y Navas, mencionan la disparidad de criterios acerca de la aplicación analógica del procedimiento judicial del internamiento para los ingresos (vid., 2006. La situación jurídica de las personas mayores. 49). Sobre los aspectos constitucionales y la restricción de la libertad que, en su caso, implica el internamiento no voluntario, vid., Sillero Crovetto. 
En este sentido, si el interesado se opone o nada puede declarar al respecto, se añade la evidencia de que al interno se le puede dispensar tratamiento psiquiátrico o imponerle medidas preventivas para evitar fugas. Por tanto, resulta incuestionable que redunda en la esfera básica de la persona, por lo que a nuestro juicio, también debería instaurarse el control judicial en estos supuestos y dotar de mayores garantías, en su caso, al sistema de atención a la dependencia.

Como se ha dicho el acceso al nuevo derecho de ciudadanía se condiciona al resultado del procedimiento descrito en la Ley 39/2006 y desarrollado por las Comunidades Autónomas. Una vez obtenido el grado y nivel que corresponda, el sujeto deviene acreedor del derecho subjetivo de ciudadanía.

En este trabajo se ha destacado el elenco de derechos y facultades previstos en el artículo 4, singularmente, la previsión que estipula y refrenda el concurso necesario de su consentimiento en el caso de ingresos en centros residenciales. Este elemento de la voluntariedad, es uno de los intereses tutelados jurídicamente "con carácter especial" y se imputa a las personas en situación de dependencia; empero, a mi juicio, nada impide la aplicación analógica a otros sujetos y circunstancias en donde se aprecie identidad de razón, como es el caso de las personas incapacitadas judicialmente o quienes encuentren comprometidas sus facultades volitivas, ostenten o no un determinado grado de dependencia.

Por fin, a esta previsión normativa del artículo 4.2 g) de la Ley 39/2006 se añaden otros elementos que permiten augurar una futura y deseable unidad jurisprudencial en las Audiencias que ratifique la necesaria legalización judicial de los ingresos en Residencias. Así, en primer lugar, el recién aprobado "Plan de modernización de la justicia", de noviembre de 2008 que tiene como eje para la efectividad de las medidas de la Carta de derecho la justicia adaptada a personas vulnerables; en segundo lugar, la Instrucción 4/2008, de 30 de julio, sobre el control y vigilancia por el Ministerio Fiscal de las tutelas de personas discapaces que persiste en la necesaria ratificación judicial de los ingresos residenciales ventilada por los trámites de la jurisdicción voluntaria; por último, la prevista adaptación de los procedimientos de modificación de la capacidad de obrar a la Convención Internacional sobre los Derechos de las personas con discapacidad.

En buena lógica, si a la oposición o avoluntariedad al ingreso en Centro residenciales se añade la evidencia de que a presencia de determinadas circunstancias cognitivas del sujeto afectado, le pueden ser impuestas medidas preventivas de fugas e, incluso, su inmovilización, ciertamente nos encontramos ante supuestos que al redundar en la esfera básica de la persona resulta preceptiva la intervención de la autoridad judicial para homologar la privación de esta libertad deambulatoria, en beneficio tanto del interno como de los equipos que intervienen. Este procedimiento, sea ventilado en trámite de jurisdicción voluntaria o contenciosa reclama, como el resto de la Justicia, de una agilización que pasa por la mejora en la dotación presupuestaria del Poder Judicial. 


\section{Referencias bibliográficas}

Bercovitz, R. 1976. De la marginación de los locos y el Derecho. Madrid: Taurus.

Calaza López, S. 2007. Los procesos sobre la capacidad de las personas. Madrid: lustel.

Casas Planes, M $M^{a}$ D. 2007. “Reflexión acerca del daño moral al enfermo psíquico derivado de actuaciones judiciales y del funcionamiento anormal de la Administración Pública (propuesta de lege ferenda)". La Ley: 6.697.

Comisión Ministerial para la Reforma Psiquiátrica. 1985. “Documento General y Recomendaciones para la reforma psiquiátrica y la atención a la salud mental". Rev. Asoc. Esp. Neuropsiquiatría 13: 204-222.

Chimeno Cano, M. 2000. "El ingreso forzoso de ancianos en centros especializados". Aranzadi. Revista de Sentencias de Tribunales de Justicia y Audiencias Provinciales 1.

Defensor del Pueblo. 1991. Informes, estudios y documentos y recomendaciones sobre la situación jurídica y asistencial del enfermo mental en España. Madrid.

Duro Ventura, C. 1995. “El internamiento de los presuntos incapaces. Introducción. Cuestiones procesales". Pp. 9-38 en Salud Mental y justicia. Cuadernos de Derecho Judicial. Madrid: Consejo General del Poder Judicial.

Gete-Alonso, Ma C. y Navas, S. 2006. “La situación jurídica de las personas mayores." Pp 37-70 en Los derechos de las personas mayores. Madrid: Dykinson.

Lacaba Sánchez, F. 1995. “El internamiento de los presuntos incapaces. Aspectos materiales". Pp. 39 -90 en Salud Mental y justicia. Cuadernos de Derecho Judicial. Madrid: Consejo General del Poder Judicial.

Lacruz Berdejo, J.L. 1978. Elementos de Derecho Civil. Barcelona: José Ma Bosch editor.

Lasarte Álvarez, C. 2010. Principios de Derecho civil, tomo 1, Parte General y Derecho de la persona. Madrid: Marcial Pons.

Lasarte Álvarez, C. 2010. Principios de Derecho civil, tomo 6, Derecho de Familia. Madrid: Marcial Pons.

Ministerio de Gobernación. 1885. "Real Decreto de 19 de mayo." Gaceta de Madrid n 141: 511, 20 de diciembre de 2010.

Ministerio de Gobernación. 1925. "Real Orden de 28 de julio". Gaceta de Madrid n²10: 661, 20 de diciembre de 2010.

Ministerio de Gobernación. 1931. "Decreto de 3 de julio". Gaceta de Madrid n 188: 186189 , 20 de diciembre de 2010.

Ministerio de Gobernación. 1932. "Decreto de 31 de mayo." Gaceta de Madrid n 153: 186-1891.603-1.604, 20 de diciembre de 2010.

Martín Pérez, J.A. 2004. “El internamiento o ingreso de personas mayores en centros geriátricos. Acerca de la procedencia de autorización judicial cuando el ingreso es involuntario". Pp. 167-192 en Protección jurídica de los mayores. Madrid: La Ley.

Moretón Sanz, Ma F. 2010. “La intervención judicial en los internamientos psiquiátricos: cuestiones sobre su aplicabilidad a los ingresos no voluntarios en residencias de mayores". Pp. 601 a 620 en Cuestiones actuales de la jurisdicción en España. Tomo I. Madrid: Dykinson-Real Academia de Jurisprudencia y Legislación.

Moretón Sanz, Ma F. 2010. "Aspetti civili di un nuovo diritto soggettivo di cittadinanza: la legge spagnola sull'autonomia personales e l'assistenza alle persone in stato di dipendenza". II diritto di famiglia e delle persona XXXIV-4: 1871-1904. 
Plaza Penadés, J. 2002. "La Ley 41/2002, básica sobre autonomía del paciente, información y documentación clínica". Actualidad jurídica Aranzadi 562: 1-2.

Serrano García, E. 2004. "Discapacidad e Incapacidad en la Ley 41/2003, de 18 de noviembre." Pp. 93-130 en Estudios de Derecho Civil: homenaje a Serrano García. Valladolid: Universidad de Valladolid.

Sillero Crovetto, B. 2007. "El internamiento no voluntario por razón de trastorno psíquico." Pp. 162-178 en La protección de las personas mayores. Madrid: Tecnos.

Zurita Martín, I. 2008. "El internamiento de personas mayores en centros geriátricos o residenciales". Pp. 19-66 en Responsabilidad derivada del internamiento de personas mayores dependientes en centros residenciales. Barcelona: Bosch. 


\section{comunitania)}

\section{Presentación/Presentation}

Antonio López Peláez

Presentación: Comunitania y Estado de Bienestar

Juan de Dios Izquierdo

\section{ARTICULOS/ARTICLES}

TThe current economic crisis in Ireland: Why social work needs to be part of the challenge to a discredited system / La actual crisis económica en Irlanda: ¿Por qué el trabajo social tiene que ser parte del desafío a un sistema desacreditado? Brid Featherstone

Welfare State and social policies in a time of economic crisis. The case of Denmark / Estados de Bienestar y las politicas

sociales en tiempos de crisis económica. El caso de Dinamarca

Bent Greve

Different routes to social security in Europe: social protection or social invesment (What determines the perception of social risks in relation to unemployment, care responsibilities and poverty? / Rutas diferentes para la seguridad social en Europa: Protección Social o Inversión Social. ¿Qué determina la percepción de los riesgos sociales relacionados con el desempleo, las responsabilidades asistenciales y la pobreza?

Anders Ejrnaes y Thomas P. Boje

La inacabada reforma psiquiátrica española: cuestiones sobre internamientos psiquiátricos no voluntarios y la ausencia de control judicial en los ingresos geriátricos / Involuntary psychiatric hospitalization under spanish law: applicability of judicial control of psychiatric hospitalization to geriatric admissions

$M^{a}$ Fernanda Moretón Sanz

La conciliación laboral y familiar en el modelo de flexiguridad en España desde una perspectiva de género / Flexicurity and work- family life balance in Spain from a gender perspective

Almudena Moreno Mínguez

La Convención ONU de 13 de diciembre de 2006: impulsando los derechos de las personas con discapacidad/The UN Convention of 13th December 2006: promoting the rights of disabled people Inmaculada Vivas Tesón

\section{RESEIIAS/REVIEWS}

Sagrario Segado Sánchez-Cabezudo. Nuevas tendencias en el Trabajo Social con Familias. Una propuesta para la práctica desde el empowerment New Trends in Social Work with Families. A Proposal for the practice from the empowerment. Madrid, Trotta 2011 (por Miguel del Fresno García)

Felipe Centellés, Rubén Darío Torres Kumbrián (eds.). La Fractura Social de Género en la Unión Europea. Los casos de Polonia y España / Social Gender Divide in the European Union. The cases of Poland and Spain. Toledo, Azacanes 2010 (por Patricia López Peláez)

Miguel del Fresno García. Retos para la intervención social con familias en el siglo XXI. Consumo, ocio, cultura, tecnología e hijos / Challenges for social intervention with families in the XXI century. Consumption, leisure, technology and children Madrid, Trotta 2011 (por Sagrario Segado Sánchez-Cabezudo)

Tomás Fernández García, Agnieszka Flisek, Grazyna Grudzińska, Urszula Lugowska, Rubén Darío Torres Kumbrián (eds.) América Latina: dos siglos de Independencia. Fracturas sociales, políticas y culturales / Latin America: two centuries of independence. Social, political and cultural divides. Varsovia, Instituto de Estudios Ibéricos e Iberoamericanos de la Universidad de Varsovia 2010 (por Katarsyna Moszczyńska)

Grażyna Grudizińska, Carolina Kumor, Katarzna Moszczyńska, Rubén Darío Torres Kumbrián (eds.). Transición en retrospectiva: los casos de Polonia y España / Retrospective transition: Poland and Spain cases. Varsovia, Instituto de Estudios Ibéricos e Iberoamericanos de la Universidad de Varsovia 2009 (por Laura Martínez Murgui)

Carlos Lasarte Álvarez, Fernanda Moretón Sanz (coords.). Residencias y alojamientos alternativos para personas mayores en situación de dependencia (Aspectos legales de la gestión, coordinación y acreditación en el SAAD de los servicios residenciales. Relevancia de los centros estatales de referencia y de la responsabilidad corporativa en la política social) / Homes and alternative housing for the elderly dependent (Legal aspects of management, coordination and accreditation of residential services SAAD. Relevance of main state institutions and corporate responsibility in social policies). Madrid Colex 2010 (por María Luz Rivera Fernández) 